\title{
Spatial Distribution and Associated Factors of Institutional Delivery Among Reproductive-Age Women (15-49 Years) in Ethiopia: The Case of Ethiopian Demographic and Health Survey 2016 Data
}

Daniel Sisay ( $\square$ Danzsis20@gmail.com )

Dilla University College of Health Sciences https://orcid.org/0000-0001-5734-3408

Temesgen Muche

Dilla University College of Health Sciences

Helen Ali

Dilla University College of Health Sciences

Research article

Keywords: Institutional delivery, spatial distribution, associated factors, Multilevel Model

Posted Date: September 8th, 2020

DOl: https://doi.org/10.21203/rs.3.rs-62965/v1

License: (1) (i) This work is licensed under a Creative Commons Attribution 4.0 International License. Read Full License 


\section{Abstract}

Background: Globally, there were an estimated 289,000 maternal deaths in 2013, yielding Maternal Mortality Rate (MMR) of 210 maternal deaths per 100,000 live births. Still, now maternal mortality in Ethiopia is the highest in the world.

Methods: This study is a secondary data analysis of the 2016 EDHS. A total of 7590 women who gave birth in the last 5 years preceding the survey were included in the analysis was carried out by using Geographic information system and clusters with high and low hotspots with institutional delivery were identified using Sat Scan spatial statistical analysis. A multilevel multivariable mixed-effect logistic regression was used to identify factors associated with institutional delivery.

Result: In this study, 33.25\% of women who gave birth in the last 5 years preceding the survey were delivered at the health institution. The finding also indicated that the spatial distribution of institutional delivery was non-random in the country. At the individual level, the riches (AOR=2.18,95\%Cl:1.39-3.41), higher education(AOR=3.89,95\% $\mathrm{Cl}: 1.51-10.01)$, four and above the number of antenatal care visits $(\mathrm{AOR}=6.57,95 \% \mathrm{Cl}: 4.83-8.94)$ and parity more than two children(AOR=0.48,95\% $\mathrm{Cl}: 0.34-0.68)$, and at the community level, higher education ( $A O R=1.70,95 \% \mathrm{Cl}: 1.22-2.36)$, urban residence (AOR=5.30, 95\% Cl:3.109.06), were variables that had achieved statically significant association for utilization of institutional delivery

Conclusions: This study identified a spatial cluster of institutional delivery of Somali and Afar region have low utilization rates and Addis Ababa and Tigray regions have the highest utilization rate. The significant associated factors of institution delivery were Individual factor of woman antenatal care visit, Household wealth index, Maternal education, Parity, and Community factor of Region, Place of residence, and Educational status, Therefore, to maximize health facility delivery in Ethiopia, the predictors of institutional delivery identified in this study should be given more attention by governmental and nongovernmental stakeholders

\section{Background}

Maternal mortality is one of the major challenges in Africa and its disparity between developing and developed countries is very high. The MMR in developing regions is 15 times higher than in developed regions. Sub-Saharan African countries included Ethiopia have the highest MMR in the world with an average of 500 maternal deaths per 100,000 live births, accounting for half of the world's total maternal deaths [2].

Almost three-fourths of deliveries were assisted by skilled professionals globally and only half, less than half and one-fourth of deliveries in Africa, sub-Saharan Africa, and Ethiopia were assisted by a skilled health professional in 2015 respectively[1]. 
Despite the Ethiopian government's efforts to expand health service facilities and promote institutionbased delivery service in the country, an estimated $85 \%$ of births still take place at home [3-4].

Maternal death is one of the causes of personal and social distress in families, because women have a major responsibility in most family matters, including raising children and have a major role in society [5].

Still now maternal mortality in Ethiopia, the highest in the world from comparing to other countries[6]. In 2005 EDHS, the maternal mortality ratio was 673 per 100,000 live births[7]. in the 2011 EDHS report, the maternal mortality ratio was estimated at 676 per 100,000 live births [8]. and in 2016 maternal mortality ratio 412 per 100,000 live births.

One critical strategy for reducing maternal morbidity and mortality is to ensure that every baby is delivered in a health care facility with the assistance of a skilled health care attendant. Therefore, to reduce maternal deaths, the most efficient strategy for lower-income countries is to promote childbirth at health care facilities with a referral capacity, as timely management and treatment can make the difference between life and death [9].

In Ethiopia, just like most developing countries, only $15 \%$ of births are delivered at a health facility despite more than $40 \%$ of pregnant women having at least one ANC visit during pregnancy[16]. Further, as reported in the $2005 \mathrm{EDHS}$, the majority of births at home take place in poor hygienic conditions, while only 6 percent are in a health facility and are assisted by trained personnel [17]. Based on data in the 2011 Ethiopia Demographic and Health Survey (EDHS 2011), the MMR was estimated at 676 maternal deaths per 100,000 live births [18].

\section{Methods}

\section{Study design and period}

Cross-sectional study design was conducted using the EDHS data of 2016. The study was conducted from January 18 to June 27, 2016.

\section{Study area}

The study was conducted in Ethiopia (3o-14o N and $\left.330-48^{\circ} \mathrm{E}\right)$, situated at the eastern horn of Africa. The country covers 1.1 million square kilometers and has a great geographical diversity, which ranges 4550 meters above sea level down to the Afar depression to 110 meters below sea level. There are nine regional states and two city administrations subdivided into 68 zones, 817 districts and 16,253 kebeles (lowest local administrative units of the country in the administrative structure of the country.

\section{Source population}


All reproductive women age 15-49 years old in Ethiopia who gave birth in the last 5 years preceding the survey.

\section{Study population}

All women aged 15 to 49 years in the selected enumeration areas who gave at least one birth in the last 5 years preceding the survey.

\section{Inclusion and Exclusion Criteria}

\section{Inclusion Criteria}

All women who gave birth in the past 5 years before the survey in selected enumeration areas were included.

\section{Exclusion Criteria}

Women with unknown places of delivery out of the geographical positioning system were excluded.

\section{Sample Size Estimation}

\section{A total of 15683 women aged 15-49 were interviewed in 2016 Ethiopian demographic health survey data (EDHS) 8490 women were excluded because they didn't have a birth in the five years preceding the survey 7590 women's have at least one birth in five years before the interview was included.}

\section{Sampling procedures}

Administratively, regions in Ethiopia are divided into zones, and zones into administrative units called woreda. Each woreda is further subdivided into the lowest administrative unit, called kebeles. During the 2007 census, each kebele was subdivided into census enumeration areas (EA), which were convenient for the implementation of the census.

A stratified two-stage cluster sampling procedure was employed where EA is the sampling unit for the first stage and households for the second stage. In 2016 EDHS, a total of 645 EAs (202 in urban areas and 443 in rural areas) were selected with probability proportional to EA size (based on the 2007 housing 
and population census) and with independent selection in each sampling stratum. Of these 18,060 households were included; 7590 women.

\section{Study Variables}

\section{Dependent variable}

Institutional delivery (Yes or No)

\section{Independent Variables}

Individual Level of Institutional Variables

\begin{tabular}{ll}
\hline Socio-demographic Factors & Obstetrics Factors \\
\hline Age at first birth & Antenatal care service \\
\hline Husband's education & Parity \\
\hline Religion & Birth order \\
\hline Residence & \\
\hline Maternal education & \\
\hline Wealth index & \\
\hline Maternal age & \\
\hline Marital status &
\end{tabular}

Community Level of Institutional Variables

Region (Pastoralist, Agrarian, and City)

Place of residence

Community-level of poverty

Community-level of education

\section{Operational definition}


Institutional delivery: The main response variable in this study was institutional delivery whether women had for the most recent live birth or not by assessed the EDHS place of delivery by asking women "Where did you give birth?

' 1 ' coded as if the woman gave birth to a health institution (Governmental and Non-governmental health center) ' 0 ' coded as if the women gave birth elsewhere

Antenatal care utilization: Having at least one visit for ANC.

Community-defined as based on the primary sample unit in the EDHS data. Community-level variables were driven by aggregating individual-level variables, the aggregated were computed using average values of the proportion of women in each category of a given variable based on national median values the aggregated values categorized into groups (42).

Community poverty: the proportion of women in the community those live households in the lower (poor) quintile of wealth index; categorized as high (proportion of women greater than median national value), and whereas low (proportion of women below the median national value).

Community education: the proportion of women in the community who primary and secondary, categorized as high (proportion of women greater than median national value) whereas low (proportion of women below-median national value).

Region: The 11 regions of Ethiopia, which are delineated for administrative purposes, were categorized into three contextual regions pastoralist(Afar, Gambella, Benishangulgumez and Somali) Agrarian(Amhara, Tigris, Oromia, and SNNP) and City (A.A, Diredewa, and Hariri) defined based on the living conditions of their population (43)

\section{Data collection and quality assurance}

\section{Data Source}

Data were obtained from the nationally representative 2016 Ethiopian Demographic and Health Survey (EDHS) which used a two-stage cluster sampling design with rural-urban and regions as strata. Approval letter for the use of this data was gained from the Measure DHS.

\section{Methods of data analysis}

First data Extracted and cleaning by Stata 14.1 version. A multi-level logistic regression analysis technique was employed in this study to account for the hierarchal structure of the DHS data and the binary response of the outcome variable Bivariate multilevel logistic regression analysis was performed to estimate the crude odds ratios at $95 \%$ confidence interval and those variables which were statistically 
significant were considered in the multivariate analysis. Finally, multivariate multilevel logistic regression analysis was performed to estimate the adjusted odds ratios and to estimate the extent of random variations between communities. In the multilevel models, the fixed effects (measures of association) estimate the association between the likelihood of institutional delivery and the individual and community level factors and were expressed as odds ratio with their $95 \%$ confidence intervals. The random effects are the measures of variation in institutional delivery across communities expressed as Intracluster Correlation Coefficient (ICC) and Proportional Change in Variance (PCV).

Model comparison was conducted by using the Log-Likelihood ratio test and the model that maximum LLR was selected as a better-fitted model. Geographical Information System (ArcGIS version 10.6) and spatial Sat scan was used to analyze spatial data.

\section{Spatial Autocorrelation Analysis}

The spatial autocorrelation (Global Moran's I) statistic measures were used to evaluate whether the institutional delivery patterns are dispersed, clustered, or randomly distributed in the study area. Calculated Moran's I values close to -1 indicate institutional delivery Is randomly distributed whereas Moran's I close to +1 indicate institutional delivery clustered distributed. A statistically significant Moran's I $(p<0.05)$ leads to rejection of the null hypothesis and indicates the presence of spatial autocorrelation. Local Moran's I will be used to investigate the local level cluster locations of institutional delivery. Local Moran's I measure whether there were positively correlated (high-high and low-low) clusters or negatively correlated (high-low and low-high) clusters of high values (High-High), and clusters of low values (LowLow). It also measures outlier in which high value is surrounded primarily by low values, and an outlier in which a low value is surrounded primarily by high values. Value for ' $I$ ' indicated that a case is surrounded by cases with dissimilar values; this case is an outlier.

\section{Hot spot analysis (Getis-OrdGi* statistic)}

Gettis-OrdGi* statistics were computed to measure how spatial autocorrelation varies over the study location by calculating $\mathrm{Gi}^{\star}$ statistic for each area. Z-score is computed to determine the statistical significance of clustering, and the $\mathrm{p}$-value computed for the significance. The $\mathrm{p}$-value associated with a $95 \%$ confidence level is 0.05 . If the $z$-score is between -1.96 and +1.96 , the $p$-value would be larger than 0.05 , and could not reject the null hypothesis; the pattern exhibited could very likely be the result of random spatial processes. If the z-score falls outside the range, the observed spatial pattern is probably too unusual to be the result of random chance, and the p-value would be small to reflect this. In this case, it is possible to reject the null hypothesis and proceed with figuring out what might be causing the statistically significant spatial pattern in the data. Statistical output with high Gi* indicates "hotspot" whereas low $\mathrm{Gi}^{\star}$ means a cold spot.

\section{Incremental analysis}


Incremental spatial autocorrelation measures spatial autocorrelation for a series of distances and optionally creates a line graph of those distances and their corresponding z-scores. Statistically significant peak z-scores indicate distances where spatial processes promoting clustering are most pronounced. These peak distances are often appropriate values to use for tools with a Distance Band or Distance Radius parameter.

\section{Incremental spatial autocorrelation}

The incremental spatial autocorrelation of institutional delivery utilization showed that the maximum peak, where the spatial clustering is highly significant at a distance of 151366.65 meters, with a corresponding z-score of 25.53 ( $p$-value $<, 0.01$ ).

\section{Ethical consideration}

Ethical clearance was obtained from the Institutional Review Board (IRB) of the Institute of Public Health, College of Medicine and Health Sciences, University of Gondar. The survey data was received from the Measure DHS International Program which authorized the data-sets. All the data used in this study are publicly available, aggregated secondary data with not having any personal identifying information that can be linked to particular individuals, communities, or study participants. Confidentiality of data was maintained anonymously (See Additional file 3).

\section{Results}

\section{Socio-demographic characteristics of study participants}

In this study, a total of 7590 women with their most recent birth in the five years preceding the 2016 EDHS survey were included in the analysis. Thirty-three percent of live births in the 5 years before the survey was delivered in a health facility. About one-fourths (24\%) of participants were $15-24$ years old age, and almost ninety percent $6620(87 \%)$ were rural residents and the majority of women who participated in the survey were orthodox Christians. Regarding the educational status of the participant's 4791(63\%) has no education and 1654 (22\%) were in the poorer wealth quintile (See Additional file 2).

Table 2: Sociodemographic characteristics of both individual and community level of respondents, 2016 EDHS

\section{Prevalence of institutional delivery across regions}

The prevalence of institutional delivery utilization varies across the regions of the country. The highest and the lowest prevalence were observed in Addis Ababa (96\%) and Afar (19.0\%) regions respectively (Figure 1). 


\section{Spatial analysis of Geographic information system}

\section{Incremental analysis}

Incremental spatial autocorrelation measures spatial autocorrelation for a series of distances and optionally creates a line graph of those distances and their corresponding z-scores. Statistically significant peak z-scores indicate distances where spatial processes promoting clustering are most pronounced. These peak distances are often appropriate values to use for tools with a Distance Band or Distance Radius parameter.

\section{Spatial Autocorrelation Report}

Spatial autocorrelation in GIS helps understand the degree to which one object is similar to other nearby objects and measures how much close objects are in comparison with other close objects. Analysis of spatial autocorrelation of Institutional delivery by its global Moran's I, the value of dispersed (Moran's I close to-1), random (0) or clustered (Moran's I close to +1 ). Then our study Global Moran's I values are 0.42 ( $p$-value $<0.001$ ) indicated that there was significant clustering of Institutional delivery in the study area. On the right side of the clustered patterns show that more distribution occurred in the study area. The bright red and blue colors (to the end tails) indicate an increased significance level (Figure 2).

Figure 2: Spatial autocorrelation for distribution of Institutional Delivery in Ethiopia, 2016

\section{Hot Spot Analysis of institutional delivery across regions of Ethiopia}

Hot spot and cold spot analysis of institutional delivery in Ethiopia, 2016. Red color shows significant areas (clusters of institutional delivery). Whereas blue color shows significant home delivery areas. When the Z-score increases to both directions (+/), its significance level also increases. Positive Z-score Shows Place of High utilization of institutional delivery However Negative Z-score shows a place of low institutional delivery (Risk of Home delivery) across regions such as Afar, Somali, Beneshangulgumaz and west Oromia (Figure 3).

Figure 3: Hot spot analysis of Institutional Delivery in Ethiopia, EDHS 2016

\section{Cluster and Outlier of institutional delivery across regions}

High-cluster: indicated that high rates of institutional delivery women's surrounded by similar characteristics, found regions of Addis Ababa, East Tigray, Dire Dawa, and Harari 
High-Outlier: indicated that high rates of institutional delivery women's surrounded by low rates of institutional delivery women's, found regions of Amhara, West Oromia,

Low-Outlier: indicated that low distribution of institutional delivery surrounded by the high distribution of institutional delivery found regions of Central Tigray, Dire Dewa, and Oromia

Low-Cluster: indicated that low distribution of institutional delivery surrounded by similar characteristics. found regions of Afar, Somali. Central Amhara, Benishangulgumez (Figure 4).

Figure 4: Cluster and Outlier of institutional delivery in Ethiopia, 2016

\section{Spatial interpolation across the region of Ethiopia EDHS 2016}

The map created by continuous images produced by interpolating Kriging interpolation method predicting unknown values at other locations. Red Color indicated that predicted High utilization number of institutional delivery. Found that regions of Addis Ababa, Tigray, Diredewa, Hariri, and Gambella Green Color predicted a low proportion of utilization of institutional delivery. Found that regions of the central and northern parts of Afar, eastern Somali, Beneshangulgumaz, and Eastern part of Oromia (Figure 5).

Figure 5: Spatial interpolation of institutional delivery areas across regions in Ethiopia.

\section{Determinants of Institutional- Delivery}

\section{Effect of individual women characteristics on the place of delivery}

Women who had Primary education 1.44 times $(A O R[95 \% \mathrm{Cl}]=1.40(1.11-1.77)$, secondary education 3.25 times $($ AOR $[95 \% \mathrm{Cl}]=3.25(2.03-5.19)$, Higher education 3.98 times $(\mathrm{AOR}[95 \% \mathrm{Cl}]=3.98(1.51-10.01)$ were more likely to give birth at the health facility as compared to no education. The wealth index is a significant predictor of the place of delivery, Women who are Poorer 1.46 times (AOR $[95 \% \mathrm{Cl}]=1.46(1.03-$ 2.09), and Richest 2.18 times (AOR $[95 \% \mathrm{Cl}]=2.18(1.39-3.41)$ more likely to give birth at health institution as compared to poorest. women who had more than one antenatal care visit were 3.75 times (AOR $[95 \% \mathrm{Cl}]=3.75(2.76-5.10)$ and Women who had more than four antenatal care visits were 6.57 times (AOR $[95 \% \mathrm{Cl}]=6.57(4.83-8.94)$ were more likely to give birth in health institutions as compared to a woman who had no antenatal care visit service. Regarding Parity Women who had $2-4$ children $52 \%(\mathrm{AOR}[95 \% \mathrm{Cl}]=$ $0.48(0.34-0.68)$ less likely to deliver at the health facility as compared to women who had one child. The study aimed to show if the characteristics of the clusters in which women lived would have an effect on their decision about the place of delivery. Related to a place of residence, Urban clusters had more odds to have a higher proportion of women giving birth at institution 5.30 times $(A O R(95 \% \mathrm{Cl})=5.30(3.10-$ 9.06) in the community. A high proportion of educated women living in communities had $70 \%$ or higher $(\mathrm{AOR}=1.70 ; 95 \% \mathrm{Cl} 1.70(1.22-2.36)$ chance of institutional delivery as compared to women living in 
communities with a low proportion of educated. The odds health facility delivery among women living in Pastoralist community is reduced by $70 \%(\mathrm{AOR}=0.30 ; 95 \% \mathrm{Cl} 0.30(0.19-0.48)$ and similarly women living Agrarian community had 55\% (AOR $=0.45 ; 95 \% \mathrm{Cl} 0.45(0.30-0.69)$ reduction to deliver at the health facility as compared with women in city communities (See Additional file 2).

Table 2: Shows Model comparison using parameters (group level factors, individual level factors and null model for 2016 EDHS

\section{Random effect and model comparison parameters}

In the null model, about $63 \%$ of the total variation on institutional delivery was occurred at the community level and is attributable to the community-level factors. The highest MOR value (9.45) in the null model revealed there was a variation of institutional delivery between clusters. Furthermore, the highest (82.63\%) PCV in the final model (Model 4) indicates that $82.63 \%$ of the variation in institutional delivery across communities was explained by both individual and community level factors. The model fitness was checked using the Loglikiehood ratio and the model with the lowest Loglikiehood ratio (Model 4) was the best-fitted model(Table 3).

Table 3 Random effect and model comparison for factors associated with institutional delivery Ethiopia, 2016

\begin{tabular}{|lllll|}
\hline Parameters & Model 1 & Model 2 & Model 3 & Model 4 \\
\hline ICC & $63 \%$ & $24 \%$ & $31 \%$ & $23 \%$ \\
\hline MOR & 9.45 & 2.62 & 3.2 & 2.54 \\
\hline PCV & Ref & $81.57 \%$ & $73.52 \%$ & $82.63 \%$ \\
\hline LLR & -3660.24 & -2993.19 & -3344.13 & -2911.60 \\
\hline
\end{tabular}

\section{Discussion}

This study aimed to explore the spatial distribution and associated factors of institutional delivery among women aged 15-49 years old: the case of EDHS 2016 data. In this study, the prevalence of institutional delivery utilization was $33.25 \%$. This result is lower than the results from India $84.9 \%$ [44] and Tanzania 74.5\%[45]. But higher than findings from the southeast part of Ethiopia 12.3\% [46]. North West of Ethiopia,12.1\% [47].Our findings show that the proportion of institutional delivery varies across the regions of the country. The highest and the lowest prevalence were observed in Addis Ababa (96\%) and Afar (19.0\%) regions respectively. The reason for the lowest utilization rate institutional delivery was lack of education and lack of access to maternal health delivery facility. 
Regarding, the geographical information system (GIS) analysis indicates that the spatial distribution of institutional delivery was non-random in the country. The Global Moran's I values of our findings are 0.42 ( $p$-value $<0.001)$ indicated that there was a statistically significant clustering of institutional delivery in the study area. And also cold spot shows areas of low institutional delivery were found in Afar, Somali and Bnshangulgumez regions. And Interpolation predicted a low proportion of institutional delivery regions are central and northern part of Afar, eastern Somali, and Beneshangulgumaz and Eastern part of Oromia. Generally, the above GIS spatial report shows that low institutional delivery found that region of Afar, Somali, Benishangulgumez, and eastern part of Oromia. This is due to a lack of access to media exposure and transport system in addition to having poor infrastructure for the utilization of institutional delivery service.

Regarding the determinants of Institutional delivery, the wealth index is a significant predictor of Institutional delivery. The odds of delivering at health institutional among mothers who had poorer and richest were 1.46 and 2.18 times respectively higher as compared to the poorest. This result similar to the study done in Bangladesh, Malawi Jacob, and Tigre northern part of Ethiopia [48-50]. This might be related to the costs needed to access health care services.

Women's education is positively associated with Institutional delivery in Ethiopia. The odds of delivering at health institutions among mothers who had primary education, secondary education, and higher educational level were 1.40, 3.25, and 3.9 times higher as compared to non-educated women. This result also similar to the study done in Ethiopia like Bahir Dar city, in Bangladesh and Pakistan. This might be due, educated women will have awareness about the risk of home delivery and the importance of maternal health services [24-26]. The number of antenatal care visits positively associated with health facility delivery. Mothers who had 1-3 and 4 and above ANC visits were 3.75 and 6.57 times more likely to deliver at health facility respectively, as compared to mothers with no ANC visit. This finding is consistent with the study done in North West Ethiopia, Somali regional states, and India. This might be due to those women attending antenatal care will be counseled about the importance of institutional delivery and birth preparedness plan [51-53].

Parity was another important predictor of institutional delivery. The odds of delivery at health facility among mothers who had the number of living children $2-4$ were reduced by $52 \%$ as compared to those who had only one child. This finding is consistent with the study conducted in Pakistan and Rural Tanzania, This is due to that Women who deliver their first child without any problem might think that they will not face the difficulty of delivering their second baby and they may not also found a person who cares for their first child to leave him at home while they go to the health institution for delivery [26-38].

Living in communities with a high proportion of educated women had a $70 \%$ higher chance of institutional delivery as compared to women living in communities with a low proportion of educated women. This study is consistent with a study done in six African countries[54]. This might be the reason In Community factor of Education could influence women's overall empowerment enhancing their ability to access information and easily absorb health messages through the media and health professionals. 
These could collectively influence mothers' awareness to seek better medical services, including delivering in health facilities.

The odds of health facility delivery among women living in the Pastoralist community are reduced by 70 $\%$ and similarly, women living in the Agrarian community had a $55 \%$ reduction to deliver at the health facility as compared with women in city communities. This due to people are very hard to reach and mostly wander to distant areas to look for animal foods, in addition to having poor infrastructure. This finding is assured by its consistency with previous studies conducted in Ethiopia and other African countries [55-57].

Place of residence was also another community-level factor which determines the choice of place of delivery. The odds of delivery at institutions for women residing in urban areas were 5.3 times higher as compared to women living in a rural area. This finding supported by national survey India and urban Bangladesh, As explained by urban women tends to benefit from increased knowledge and access to maternal health services[49-58].

\section{Conclusion}

In this study both the individual and community level characteristics were found to have a significant influence on institutional delivery and identified spatial clusters of health facility delivery in Afar and Somali Region with lowest utilization rates and Addis Ababa and Tigray with the highest utilization rate. In multivariate multilevel logistic regression analysis were antenatal care visits, household wealth index, maternal education, Parity, community level of education, residence and region were variables that had achieved statistically significant association to institutional delivery.

\section{Abbreviations}

ANC: Antenatal care, CSA: Central Statistics Agency, DHS: Demography Health Survey, EDHS: Ethiopia Demography Health Survey, EA: Enumeration Area, GLMM: Generalized Logistic Mixed Effect Regression Model, GIS: Geographic Information System, LQAS: Low-Quality Assistance Sampling, ICC: Intra Class correlation coefficient

\section{Declarations}

\section{Ethics approval and consent to participate}

For this study ethical approval was not required since this is a secondary analysis of the 2016 EDHS data. But we registered and requested access to EDHS datasets from DHS on-line archive and received approval to access and download the data files.

\section{Consent for publication}


Not applicable

\section{Availability of data and materials}

All result-based data are available within the manuscript and anyone can access the data set online from www.measuredhs.com.

\section{Competing interests}

The authors declare that they have no competing interests.

\section{Funding}

No, any funding was received from any organization.

\section{Authors' contributions}

DS conceived the topic and drafted the study as part of his MSc study, wrote up of the research proposal, analyzed the data, presented the results and wrote up the draft manuscript and involved in data analysis; TM, and HA: supervised the protocol development and revisited the manuscript critically for important intellectual content. The three authors are involved in the analysis and design of the study and also the three authors read and approved the final manuscript. DS, TM, and HA are agreed to be accountable for all aspects of the work.

DS:- has MPH in Epidemiology and Biostatistics, in the unit of epidemiology and biostatistics, School of Public health, College of Health Science and Medicine, Dilla University, Ethiopia.

TM: has an MSc. In Human Nutrition, in the unit of Human Nutrition, School of Public health, College of Health Science and Medicine, Dilla University, Ethiopia.

HA: has an MSc. In Human Nutrition, in the unit of Human Nutrition, School of Public health, College of Health Science and Medicine, Dilla University, Ethiopia.

\section{Acknowledgments}

We would like to acknowledge the MEASURE DHS program for permitting us to obtain and use the 2016 EDHS data set.

\section{References}

1. Kassebaum NJ, Barber RM, Bhutta ZA, Dandona L, Gething PW, Hay SI et al. Kassebaum NJ, Barber RM, Bhutta ZA, Dandona L, Gething PW, Hay SI, et al. Global, regional, and national levels of maternal mortality, 1990-2015: a systematic analysis for the Global Burden of Disease Study 2015. The Lancet. 2016;388(10053):1775-812. 
2. Authority CS. Central Statistical Authority (CSA) [Ethiopia], and ORC Macro. 2006. Ethiopia Demographic and Health Survey 2005. Addis Ababa, Ethiopia, and Calverton, MD, USA: CSA and ORC Macro.

3. Hailu M, Gebremariam A, Alemseged F DK. 17. Hailu M, Gebremariam A, Alemseged F, Deribe K. Birth preparedness and complication readiness among pregnant women in Southern Ethiopia. PLoS One. 2011;6(6):e21432.

4. MekonnenY MA. Mekonnen Y, Mekonnen A. Factors influencing the use of maternal healthcare services in Ethiopia. J Health Popul Nutr. 2003;21(4): 374-382.

5. Mekonnen Y, Mekonnen A. Factors Influencing the Use of Maternal Healthcare Services in Ethiopia. 2015;(January 2004).

6. Central Statistical Authority (CSA) [Ethiopia], and ORC Macro. 2006. Ethiopia Demographic and Health Survey 2005. Addis Ababa, Ethiopia, and Calverton, MD, USA: CSA and ORC Macro.

7. Central Statistical Authority (CSA) [Ethiopia], and ORC Macro. 2001. Ethiopia Demographic and Health Survey 2000. Addis Ababa, Ethiopia, and Calverton, MD, USA: CSA and ORC Macro.

8. CSA [Ethiopia], and ICF International. 2012. Ethiopia Demographic and Health Survey 2011. Addis Ababa, Ethiopia, and Calverton, Maryland, USA: Central Statistical Agency and ICF International.

9. W.mortality. World Health Organization. WHO 2012 Maternal and Child Health Fact Sheet;2012.Available from: http://www.who.int/mediacentre/factsheets/fs348/en/.world health Organization. Accessed December 27, 2014.

10. Say L, Chou D, Gemmill A, Tunçalp Ö, Moller A, Daniels J, et al. Global causes of maternal death: a WHO systematic analysis. 2006;323-33.

11. 2006 MK-. Koblinsky M, Matthews Z, Hussein J, Mavalankar D, Mridha MK, Anwar I, et al. Going to scale with professional skilled care.Lancet.2006;368(9544):1377-

12. CS. A. Authority CS. Central Statistical Authority (CSA) [Ethiopia], and ORC Macro. 2006. Ethiopia Demographic and Health Survey 2005. Addis Ababa, Ethiopia, and Calverton, MD, USA: CSA and ORC Macro.

13. Garg R, Shyamsunder D, Singh T, Avtar P. HEALTH AND POPULATION: PERSPECTIVES AND ISSUES [ INCORPORATING NIHAE BULLETIN (ESTD . 1968 ) AND THE JOURNAL OF POPULATION RESEARCH (ESTD . 1974 )] VOLUME 33 Editorial: ROLE OF MEDICAL PERSONNEL IN PROMOTING. 2010;33(1).

14. Montagu D, Yamey G, Visconti A, Harding A, Yoong J. Where do poor women in developing countries give birth? a multi-country analysis of Demographic and health survey data. PLoS One. 2011;6(2).

15. Kifle MM, Kesete HF, Gaim HT, Angosom GS, Araya MB. A health facility or home delivery? Factors influencing the choice of delivery place among mothers living in rural communities of Eritrea. $J$ Health Popul Nutr. 2018;37(1):22.

16. Belay A, Sendo E. Factors determining the choice of delivery place among women of childbearing age in Dega Damot District, North West of Ethiopia: a community-based cross-sectional study. BMC Pregnancy Childbirth. 2016;1-8. 
17. Agency CS, Ababa A. Ethiopia Demographic and Health Survey.

18. Say L, Chou D, Gemmill A, Tunçalp Ö, Moller A, Daniels J et a. I. Global causes of maternal death : a WHO systematic analysis. 2006;323-33.

19. Wong KLM, Radovich E, Owolabi OO, Campbell OMR, Brady OJ, Lynch CA, et al. Why not? Understanding the spatial clustering of private facility-based delivery and financial reasons for homebirths in Nigeria. BMC Health Serv Res. 2018;18(1):1-12.

20. Agadjanian V, Hayford SR. Place, Time and Experience: Barriers to Universalization Of Institutional Child Delivery in Rural Mozambique. 2017;42(1):21-31.

21. Agency central statistics. CSA [Ethiopia] and ICF International. Ethiopia Demographic and Health Survey 2011. Addis Ababa Ethiopia and Calverton, Maryland, USA: Central Statistical Agency and ICF International; 2012.

22. W.mortality, Montagu D, Yamey G, Visconti A, Harding A, Yoong J, et al. World Health Organization. WHO 2012 Maternal and Child Health Fact Sheet; 2012. Available from: http://www.who.int/mediacentre/factsheets/fs348/en/.world health Organization. Accessed December 27, 2014. Malawi Natl Stat Off ORC Macro, .... 2011;6(March):7-8.

23. Yaya S, Bishwajit G, Ekholuenetale M. Factors associated with the utilization of institutional delivery services in Bangladesh. PLoS One. 2017;12(2):1-14.

24. G. A, M. A, T. S, Abeje G, Azage M, Setegn T. Factors associated with Institutional delivery service utilization among mothers in Bahir Dar City administration, Amhara region : a community-based cross-sectional study. Reprod Health. 2014;1-7.

25. Whitehead M. Editorial: Policy and practice. Health Educ J. 1994;53(1):1-2.

26. Access O. Determinants of institutional delivery in rural. 2011;1-12.

27. Mehari AM. Levels and Determinants of Use of Institutional Delivery Care Services among Women of Childbearing Age in Ethiopia: Analysis of EDHS 2000 and 2005 Data [WP83]. 2013;(February).

28. Titaley CR, Hunter CL, Dibley MJ, Heywood P. Why do some women still prefer traditional birth attendants and home delivery?: A qualitative study on delivery care services in West Java Province, Indonesia. BMC Pregnancy Childbirth. 2010;10.

29. Mekonnen MG, Yalew KN, Umer JY, Melese M. Determinants of delivery practices among Afar pastoralists of Ethiopia. Pan Afr Med J. 2012;13 Suppl 1(Supp 1):17.

30. A.A. F, M. D. Prevalence of institutional delivery and associated factors in Dodota Woreda (district), Oromia regional state, Ethiopia. Reprod Health [Internet]. 2012;9(1):1-6.Available from: http://www.embase.com/search/results? subaction=viewrecord\&from=export\&id=L52356794\%5Cnhttp://dx.doi.org/10.1186/1742-4755-9-33

31. Mubarik S. Effect of National Health Insurance Holding on the Choice of Health Facility for Childbirth in Ghana. Sci J Public Heal. 2016;4(1):26.

32. Tsegay R, Aregay A, Kidane K, Alemayehu M, Yohannes G. Determinant factors of home delivery among women in Northern Ethiopia: a case-control study. 2017;1-8 
33. G. A, M. A, T. S. Factors associated with Institutional delivery service utilization among mothers in Bahir Dar City administration, Amhara region: A community-based cross-sectional study. Reprod Health. 2014;1-7.

34. L Van Blerk - Area 2008 - Wiley Online Library. Ethiopian Society of Population Studies 2008.

35. Hodgkin D. Household characteristics affecting where mothers deliver in rural Kenya.

36. Shah R, Rehfuess EA, Maskey MK, Fischer R, Bhandari PB, Delius M. Factors affecting institutional delivery in rural Chitwan district of Nepal: A community-based cross-sectional study. BMC Pregnancy Childbirth. 2015;15(1):1-14.

37. Medhanit Getachew Mekonnen1,\&, Kassahun Negash Yalew1, Jemal Yesouf Umer1, Muluken Melese.

38. Ndao-Brumbley SK, Mbaruku G, Kruk ME. Parity and institutional delivery in rural Tanzania: a multilevel analysis and policy implications. 2013;(November 2012):647-57.

39. Asmeret M 2013. Asmeret, M. 2013. Levels and Determinants of Use of Institutional Delivery Care Services among Women of Childbearing Age in Ethiopia. Analysis of EDHS 2000 and 2005 Data. Calverton, Maryland, USA: ICF International.

40. Irene TO 2013. Irene, T. O. 2013. The Role of Antenatal Care in Predicting Health Facility Delivery among Women in Kenya: Further Analysis of Data from the 2008-09 KDHS, Calverton, Maryland, USA: ICF International.

41. Kahsay HGYMAGAB. Henock G. Yebyo Mussie A. Gebreselassie Alemayehu B. Kahsay. 2014. Individual and Community-Level Predictors of Home Delivery in Ethiopia: A Multilevel Mixed-Effects Analysis of the 2011 Ethiopia National Demographic and Health Survey, Calverton, Maryland.

42. Yeo $\mathrm{H}$, Alemayehu $\mathrm{M}$, Kahsay A. Why do women deliver at home? Multilevel modeling of Ethiopian national demographic and health survey data. PLoS One [Internet].2015;10(4):1-14.Available from: http://dx.doi.org/10.1371/journal.pone.0124718

43. Mekonnen ZA, Lerebo WT, Gebrehiwot TG, Abadura SA. Multilevel analysis of individual and community-level factors associated with institutional delivery in Ethiopia. BMC Res Notes. 2015;1-9.

44. Roy MP, Mohan U, Singh SK, Singh VK SA. Roy MP, Mohan U, Singh SK, Singh VK, Srivastava AK. Factors associated with the preference for delivery at the government hospitals in rural areas of Lucknow district in Uttar Pradesh. Indian J Public Health. 2013;57(4):268.

45. 2014;13(48):11 IJEH. Every A. Access to institutional delivery care and reasons for home delivery in three districts of Tanzania. Int J Equity Health. 2014;13(48):11.

46. Amano A, Gebeyehu A BZ. Institutional delivery service utilization in Munisa Woreda, South East Ethiopia. BMC Pregnancy Childbirth. 2012;12:105.

47. Shameka AT, Mazengia FA MS. Institutional delivery service utilization and associated factors among mothers who gave birth in the last 12 months in Sekela District, North West of Ethiopia. BMC Pregnancy Childbirth. 2012;12:74. 
48. Mazalale J, Kambala C, Brenner S, Chinkhumba J, Lohmann J, Mathanga DP, et al. Factors associated with delivery outside a health facility: Cross-sectional study in rural Malawi. Trop Med Int Heal. 2015;20(5):617-26.

49. Yaya S, Bishwajit G, Ekholuenetale M. Factors associated with the utilization of institutional delivery services in Bangladesh. PLoS One [Internet]. 2017;12(2):1-14. Available from: http://dx.doi.org/10.1371/journal.pone.0171573

50. Moges AY, Yaya TN. Determinants of Safe Delivery Service Utilization Among Women of Childbearing Age in Angela Sub-Woreda, Tigray, Northern Ethiopia. 2017;5(6):411-8.

51. Nejimu Biza Zepro1, Ahmed Tahir Ahmed2. Determinants of institutional delivery service utilization among pastorals of Liben Zone, Somali Regional State, Ethiopia, 2015. Int J Women's Heal [Internet]. 2016;705-12. Available from: http://dx.doi.org/10.2147/IJWH.S123189

52. Feyissa TR, Genemo GA. Determinants of Institutional Delivery among Childbearing Age Women in Western Ethiopia, 2013: Unmatched Case-Control Study. 2014;9(5):1-7.

53. AlemayehuSayih Belay ${ }^{*}$ and EndalewGemechu Sendo2 Factors determining the choice of delivery place among women of childbearing age in Dega Damot District, North West of Ethiopia: a community based cross-sectional study

54. Stephenson R, Baschieri A, Clements S, Hennink M, Madise N. Contextual influences on the use of health facilities for childbirth in Africa. Am J Public Health. 2006;96(1):84-93.

55. Aremu O, Lawoko S, Dalal K. The Influence of Individual and Contextual Socioeconomic Status on Obstetric Care Utilization in the Democratic Republic of Congo: A Population-based Study. International Journal of Preventive Medicine 2012; 3:278-85. PMID: 226. Int J Prev Med 2012; 3278-85 PMID 22624085.

56. Gabrysch S, Cousens S, Cox J, Campbell O. The Influence of Distance and Level of Care on Delivery Place in Rural Zambia: A Study of Linked National Data in a Geographic Information System. PLOS Medicine 2011; 8:1.

57. Utomo B, Sucahya P, Utami F. Priorities and realities: addressing the rich-poor gaps in health status and service access in Indonesia. International Journal for Equity in Health 2011; 10:47. DOI: 10.1186/ 1475-9276-10-47 PMID: 22067727.

58. Thind A, Mohani A, Banerjee K, Hagigi F. Where to deliver? Analysis of choice of delivery location from a national survey in India. BMC Public Health. 2008;8:1-8.

\section{Tables}

Due to technical limitations, table 1 and 2 is only available as a download in the Supplemental Files section.

\section{Figures}




\section{Regional prevance of Institutional delivery}

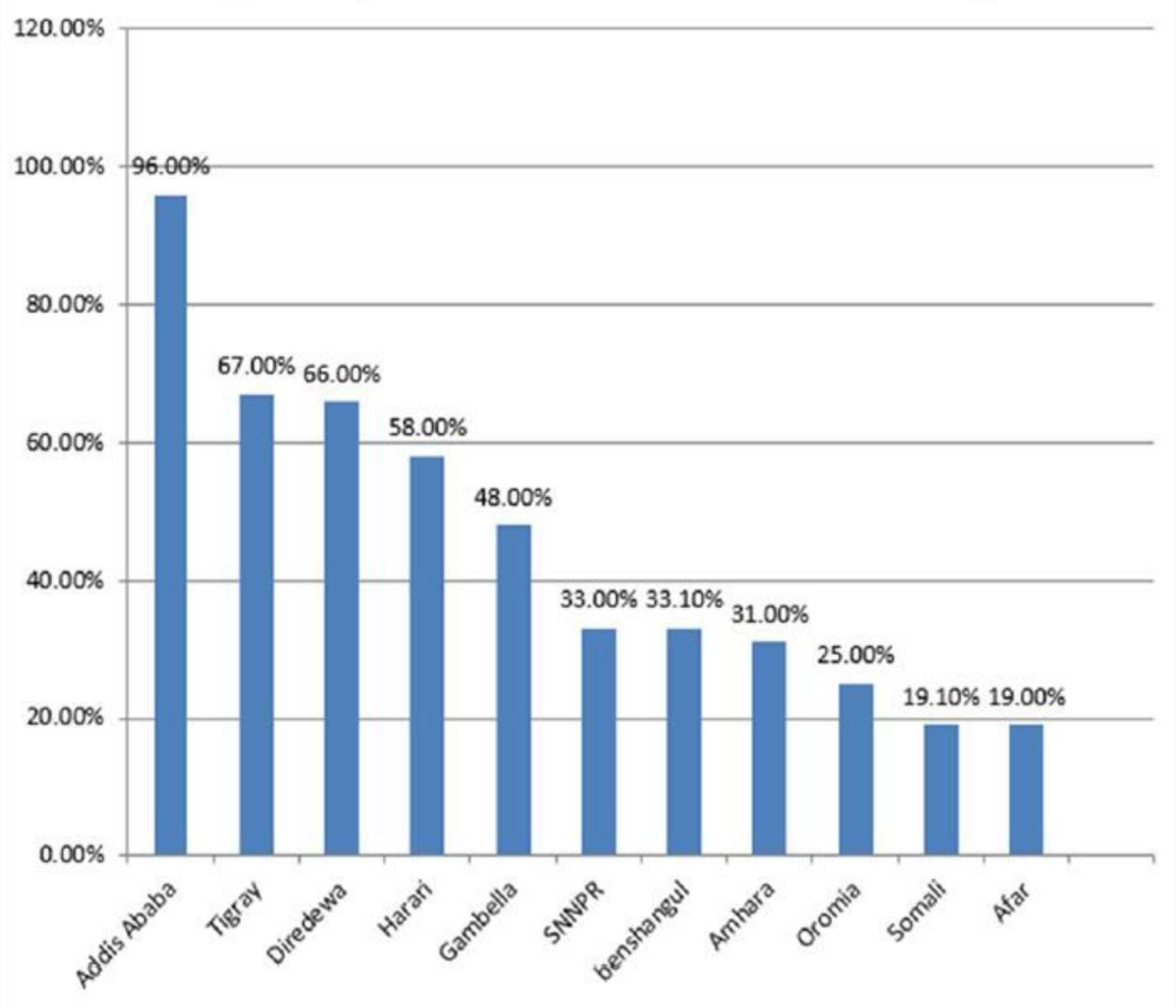

Figure 1

Regional prevalence of institutional delivery (Source; Shape file central statistical Agency, 2016) 


\section{Spatial Autocorrelation Report}

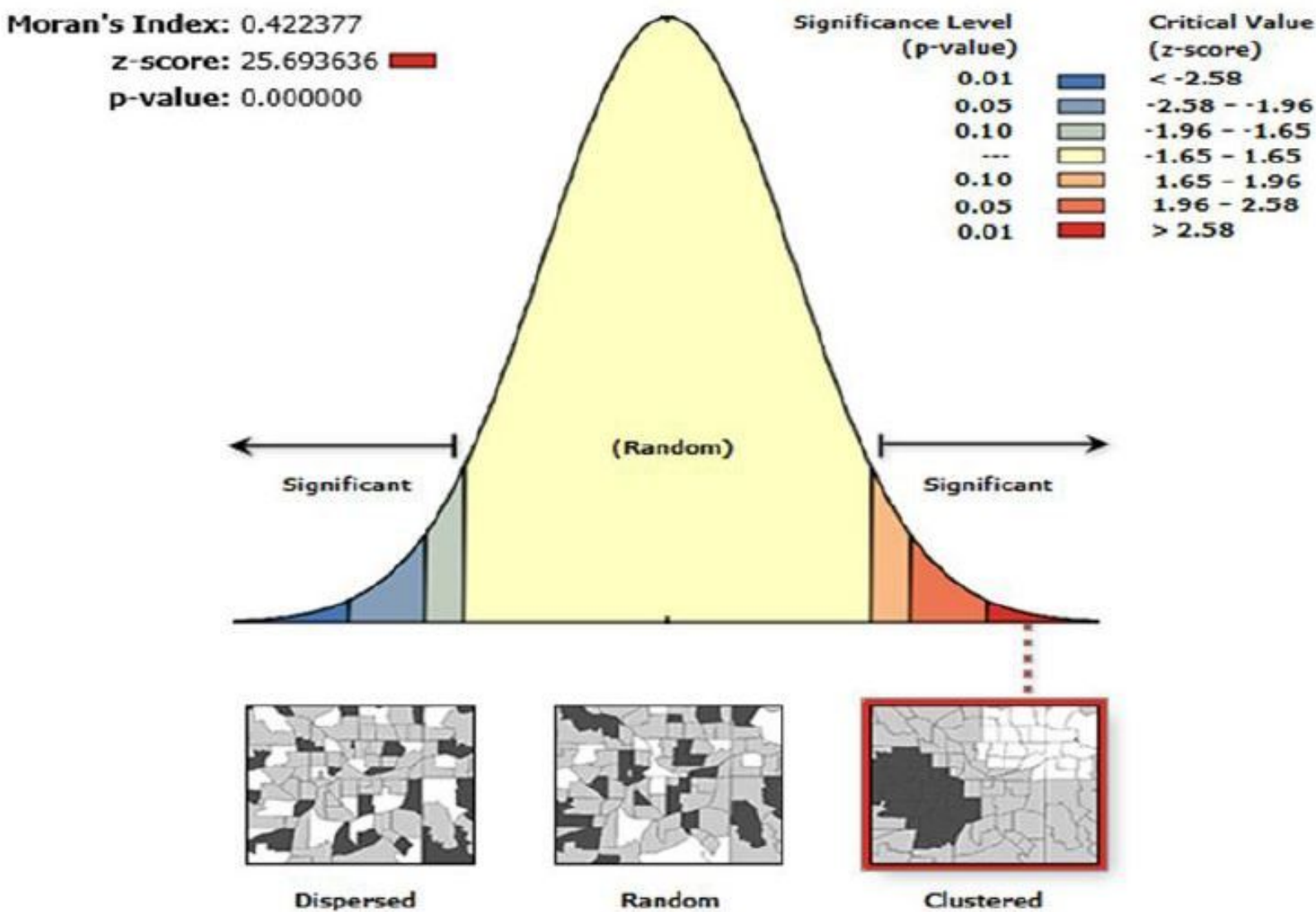

Given the $z$-score of 25.6936357777 , there is a less than $1 \%$ likelihood that this clustered pattern could be the result of random chance.

\section{Figure 2}

Spatial autocorrelation for distribution of Institutional Delivery in Ethiopia, 2016 


\section{Hot Spot Analysis Of Institutional Delivery across region of Ethiopia}

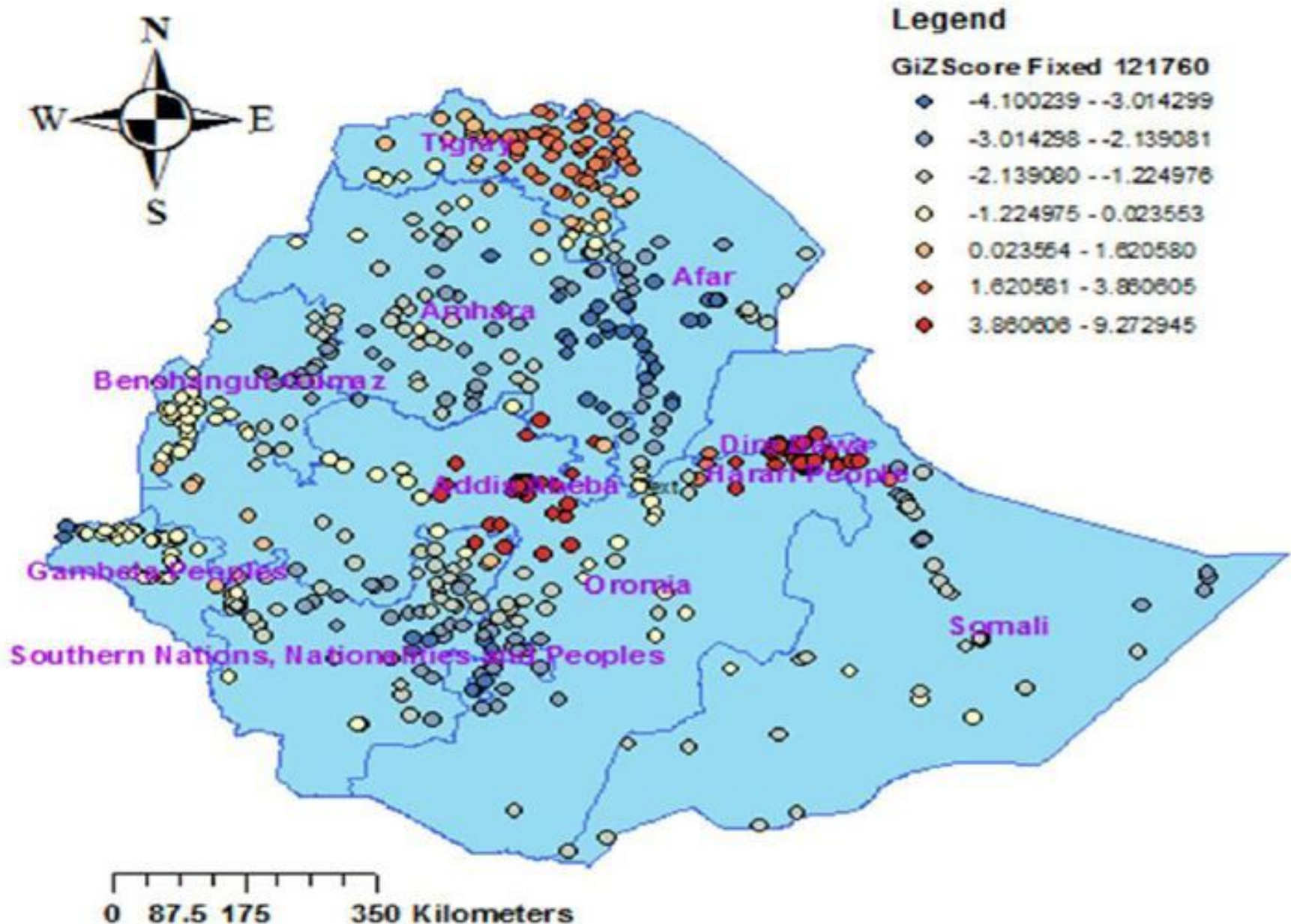

Figure 3

Hot spot analysis of Institutional Delivery in Ethiopia, EDHS 2016 


\section{Cluster outlier of instiutional delivery across regions of Ethiopia}

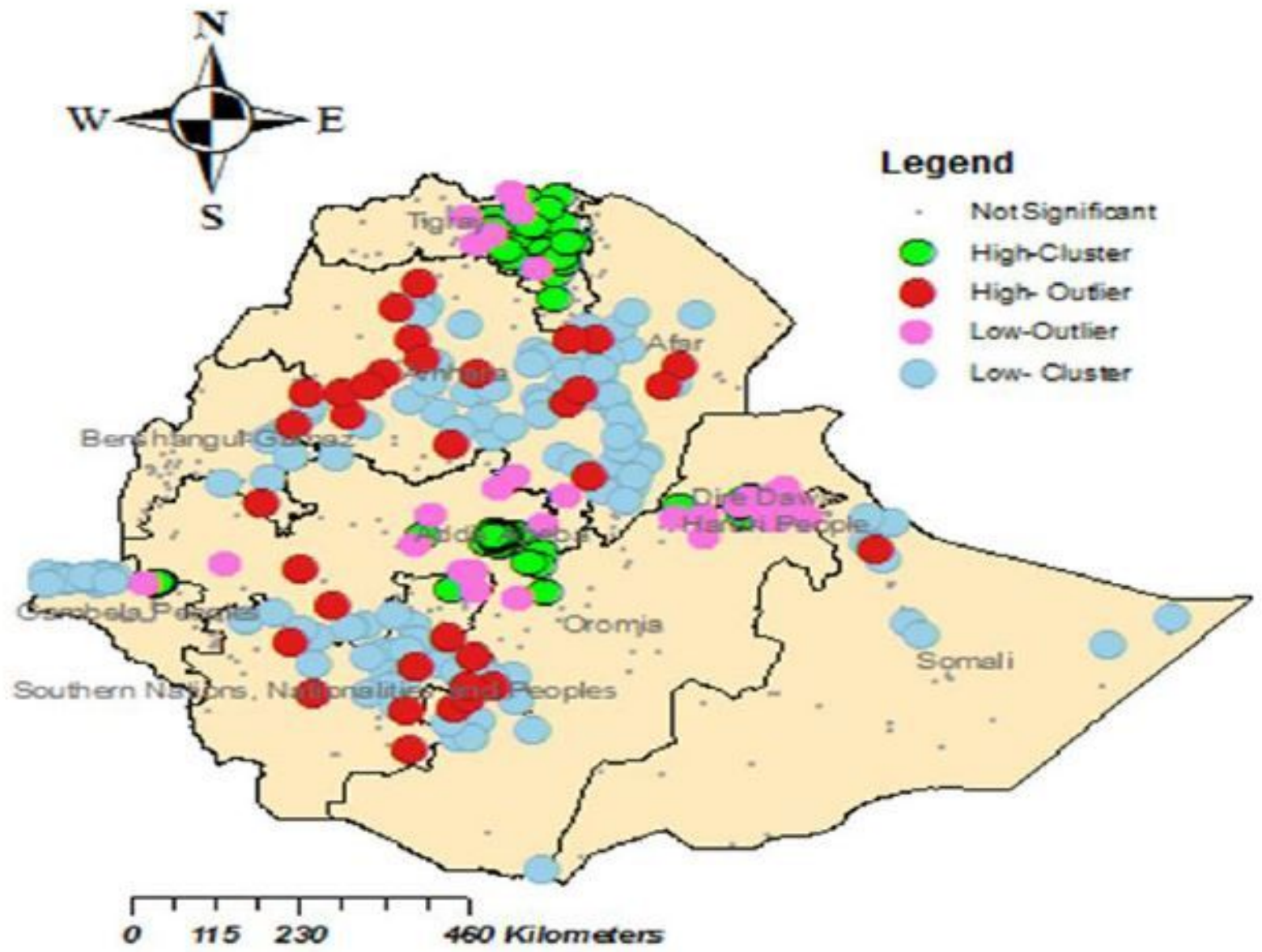

Figure 4

Cluster and Outlier of institutional delivery in Ethiopia, 2016 


\section{Spatial interpolation of institutional delivery in Ethiopia, 2016}

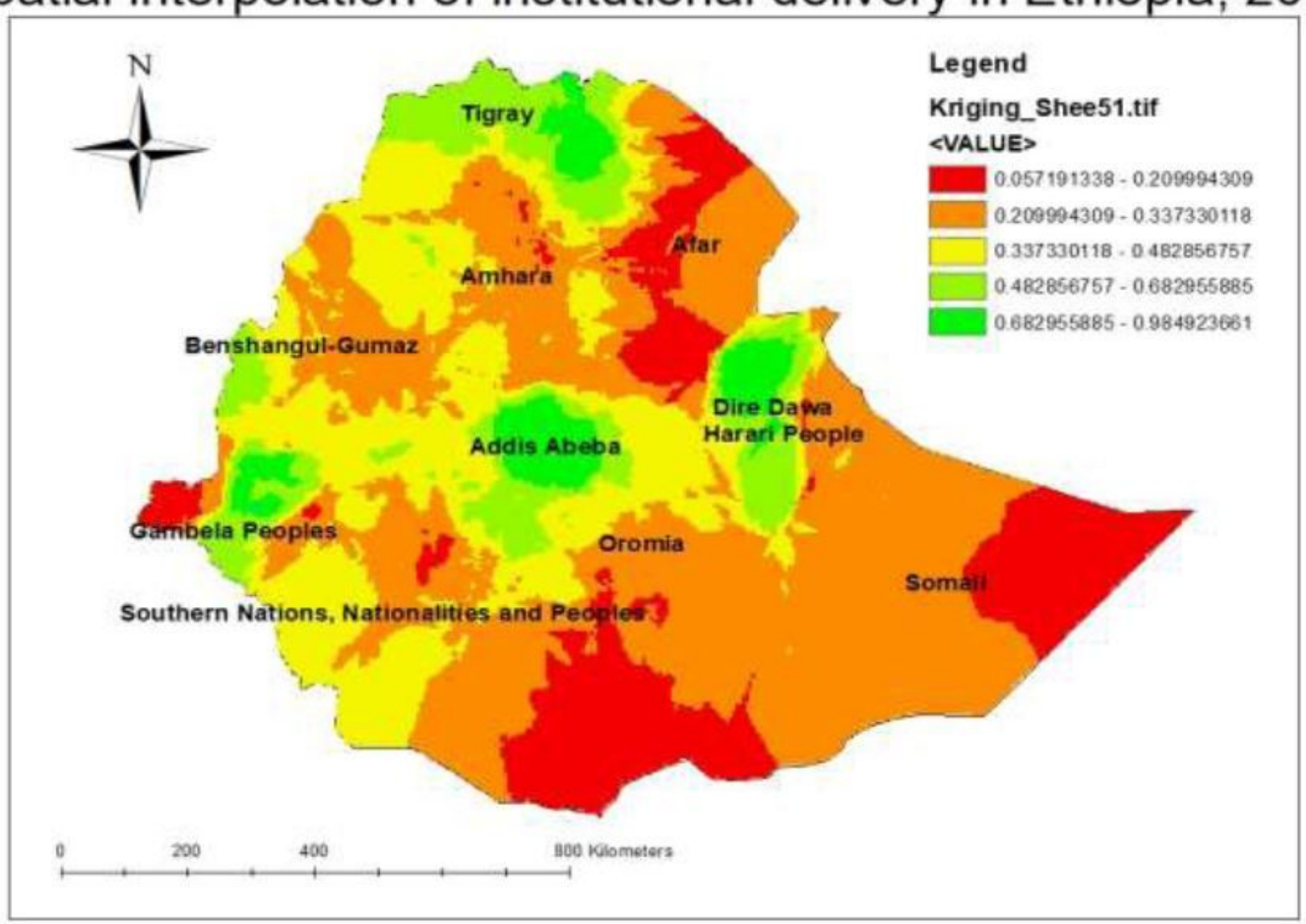

Figure 5

Spatial interpolation of institutional delivery areas across regions in Ethiopia

\section{Supplementary Files}

This is a list of supplementary files associated with this preprint. Click to download.

- Additionalfile2.pdf

- Additionalfile1.pdf 